\title{
Nodular Cystic Variant of Basal Cell Carcinoma: Perfect Correlation Between Histopathology and Confocal Microscopy
}

\author{
Cristina Vico-Alonsoํ, Uxúa Floristán-Muruzábal², Reyes Gamo-Villegas²
}

1 Department of Dermatology and Venereology, Hospital Universitario 12 de Octubre, Madrid, Spain

2 Department of Dermatology and Venereology, Hospital Universitario Fundación Alcorcón, Madrid, Spain

Key words: adenoid type basal cell carcinoma, reflectance confocal microscopy, dermoscopy

Citation: Vico-Alonso C, Floristán-Muruzábal U, Gamo-Villegas R. Nodular cystic variant of basal cell carcinoma: perfect correlation between histopathology and confocal microscopy. Dermatol Pract Concept. 2019;9(1):67-68. DOI: https://doi.org/10.5826/dpc.0901a15 Published: January 31, 2019

Copyright: @2019 Vico-Alonso et al. This is an open-access article distributed under the terms of the Creative Commons Attribution License, which permits unrestricted use, distribution, and reproduction in any medium, provided the original author and source are credited.

Funding: None.

Competing interests: The authors have no conflicts of interest to disclose.

Authorship: All authors have contributed significantly to this publication.

Corresponding author: Cristina Vico-Alonso, MD, Servicio de Dermatología, Hospital Universitario 12 de Octubre, Avenida de Córdoba s/n, 28041 Madrid, Spain. Email: c.vicoalonso@gmail.com

\section{Introduction}

A 67-year-old-woman with a history of basal cell carcinoma (BCC) and actinic keratosis presented with an asymptomatic lesion on her central forehead for the preceding 3 months. There was no significant family history of cancer.

\section{Case Presentation}

Cutaneous examination revealed a pearly white, domeshaped papule measuring $1 \times 0.7 \mathrm{~cm}$ on the central forehead with telangiectatic vessels and yellow ovoid structures at dermoscopic examination (DermLite DL3 3 Gen LLC, San Juan Capistrano, CA) (Figure 1). The rest of the skin was otherwise unremarkable. Reflectance confocal microscopy (Vivascope 1500 Multilaser, Lucid, Rochester, NY) showed a cystic lesion with hyporefractive content (Figure 2) and some hyperrefractive cells in the periphery of the cyst (Figure 2). Surgical removal was performed and histopathological examination of the hematoxylin and eosin (H\&E)-stained section revealed groups of peripheral

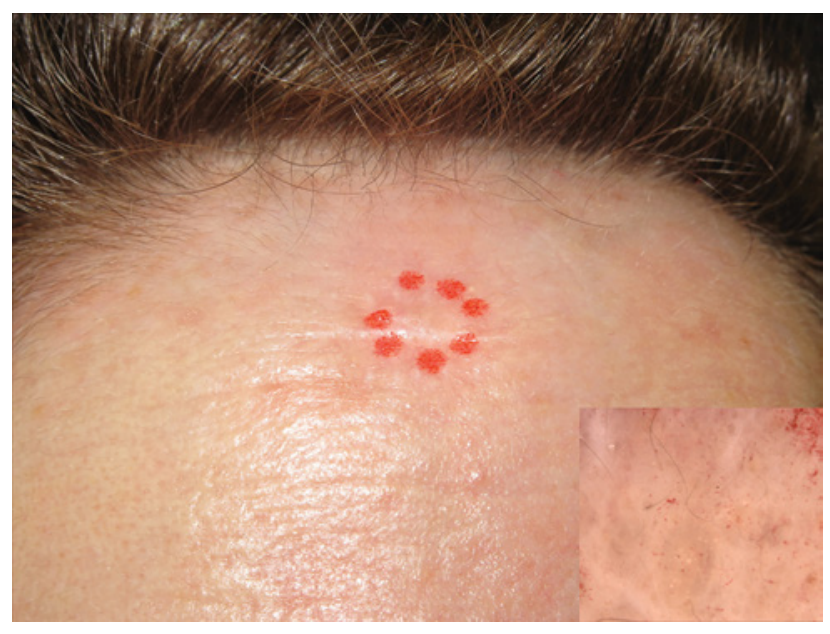

Figure 1. Dome-shaped papule, $1 \times 0.7 \mathrm{~cm}$ in diameter on the central forehead. Inset: Telangiectatic vessels and yellow ovoid structures at dermoscopy. [Copyright: (92019 Vico-Alonso et al.]

basaloid cells in a lobular pattern. The tumor contained cystic spaces of mucin (Figure 3) of different sizes, located peripherally to tumor nests. Diagnosis of nodular cystic variant of BCC was given. 


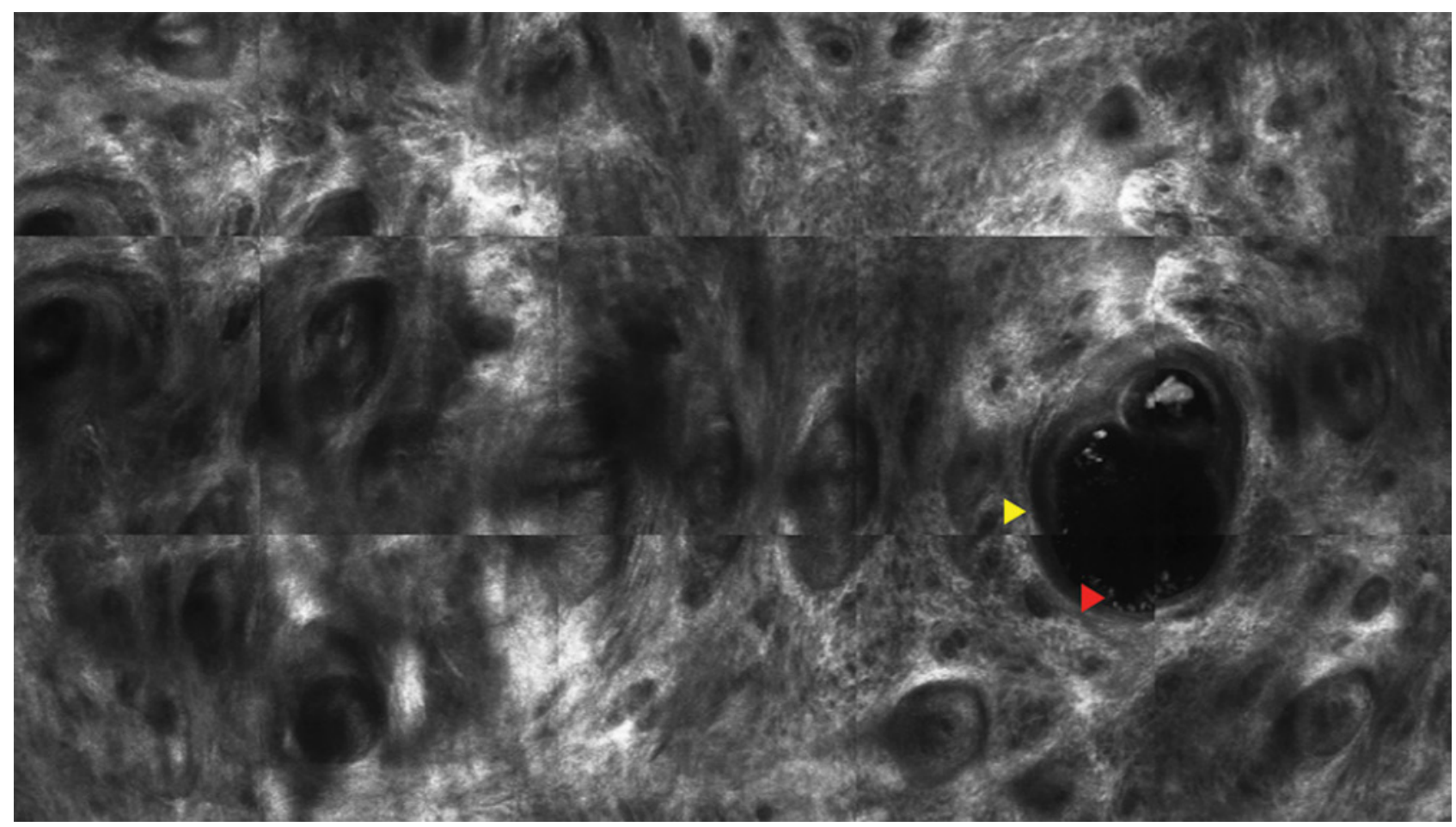

Figure 2. Reflectance confocal microscopy: Cystic lesion with hyporefractive content (yellow arrowhead) and some hyperrefractive cells (red arrowhead) in the periphery of the cyst. [Copyright: (2019 Vico-Alonso et al.]

\section{Conclusions}

Clinical and morphological subtypes of BCC include solid, micronodular, cystic, multifocal, superficial, pigmented, adenoid, infiltrating, sclerosing, keratotic, infundibulocystic, metatypical, basosquamous, and fibroepitheliomatous [1]. The classic type is nodular, which usually appears as a pearly nodule with telangiectasias, located on sun-exposed areas.

A relatively rare variant of nodular BCC is the cystic form, which shows cavities that may result from tumoral necrosis. It is a low-grade variant of conventional BCC with an estimated incidence of less than 3\% [1]. This tumor has been reported few times in literature because of its low incidence. However, the importance of making a correct diagnosis lies in the necessity to differentiate this tumor from eccrine syringofibroadenoma [2].

This case highlights the presence of a rare nodular cystic variant of BCC with a pathological and confocal microscopy correlation that may help clinicians as well as pathologists to identify this form of BCC. The presence of isolated cystic hyporefractive lesions and surrounding hyperrefractive cells helps to perfectly identify this tumor by confocal microscopy.

\section{References}

1. Yoneta A, Horimoto K, Nakahashi K, Mori S, Maeda K, Yamashita T. A case of cystic basal cell carcinoma which shows a homogenous blue/black area under dermatoscopy. J Skin Cancer. 2011;2011:450472. Epub 2010 Sep 23.

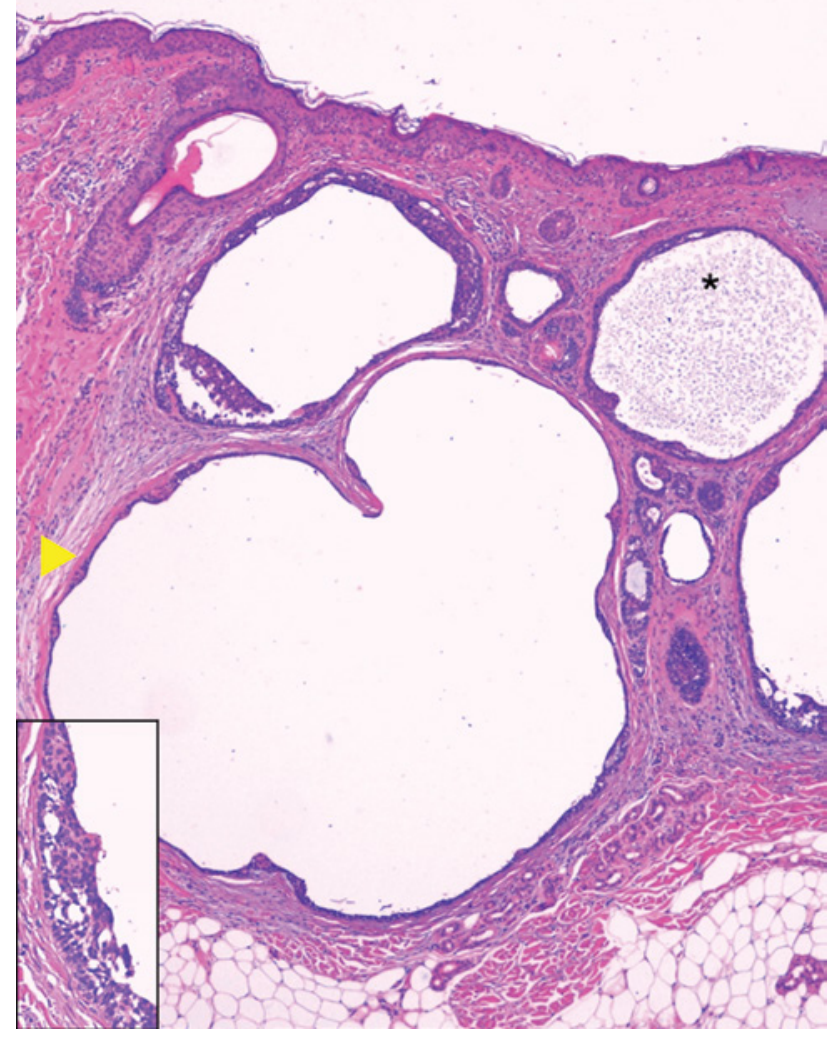

Figure 3. Groups of peripheral basaloid cells with hyporefractive content (yellow arrowhead) and mucin-filled cysts (asterisk; H\&E, $\times 100$ ). [Copyright: @2019 Vico-Alonso et al.]

2. Ruchita T, Dilpreet K, Gursheen K, et al. Nodular cystic basal cell carcinoma of the trunk: a diagnostic dilemma in an unsuspecting youth. Iran J Pathol. 2017;12(4):410-412. 